\title{
A Successful Approach to Study Skills: Go4C's Projects Strengthen Teamwork
}

\author{
http://dx.doi.org/10.3991/ijep.v6i1.5359 \\ Matthias Christoph Utesch \\ Technical University of Munich, Munich, Germany \\ Staatliche Fachober- und Berufsoberschule Technik München, Munich, Germy
}

\begin{abstract}
The Pupils' Academy of Serious Gaming at the Technical University of Munich (TUM) deploys the business game Go4C as a tool to learn study skills. Especially, the project management feature of $\mathrm{Go4C}$ is a reliable instrument to successfully strengthen teamwork skills of students at the upper vocational schools of Bavaria/ Germany. We enable the pupils to change their learning perspective from school student to university student by participating in a regular course at TUM based on projectbased learning with Go4C. The goal is to learn how to selfassess and develop those activities which are important for one's personal study skills at an early stage before leaving
\end{abstract} school.

Index Terms-business game, project management, study skills, teamwork

\section{INTRODUCTION}

In this paper we present the Pupils' Academy with Go4C at the Technical University of Munich (TUM), which, for six years now, has been a reliable instrument to successfully strengthen the study skills of students at the upper vocational schools of Bavaria/ Germany. It focuses on project-based learning with our business game $\mathrm{Go} 4 \mathrm{C}$ [1].

Following this first section on the structure of this paper, the second section will introduce our target group: the upper vocational schools of Bavaria whose specific pedagogical approach is application-oriented learning.

In the third section we will discuss those study skills which are most significant to the upper vocational schools. The fourth section will give an overview of the contents and educational objectives of the Pupils' Academy.

Based on this, in the fifth section we will explain the five phases of interaction for project-based learning with the business game Go4C. Then the sixth section will describe the Didactic Framework of Go4C and section seven will show how this framework corresponds with the study skills.

In section eight we will discuss the results of the Pupils' Academy by means of a survey. Section nine finally will draw a conclusion of our approach.

\section{THE UPPER VOCATIONAL SCHOOLS IN BAVARIA}

Historically, in Bavaria/ Germany, the access to postsecondary education was granted via the grammar school Gymnasium. Additionally, the upper vocational schools Berufsoberschule (BOS) and Fachoberschule (FOS) were established in the years 1969 and 1970. BOS and FOS provide - usually at the end of grade 12 - the
German Abitur, a final examination, which will grant access to university.

In the school year $2013 / 14$ a total of 63,722 students graduated at all types of upper secondary schools in Bavaria. 26,032 graduates - or $41 \%$ - came from vocational schools [2].

The students of BOS and FOS are young people who realized at secondary school level: "I learn best in an application-oriented way." Thus, BOS and FOS provide university entrance certifications, which focus on a project-based approach to learning.

While the students at grammar school Gymnasium benefit from an average of six years at the same school and are familiar with their learning environment, at BOS and FOS the situation is quite different. Here the students have to start all over in a completely new environment: new school, new teachers, and new social structures in the classes. Just imagine, today there are more than thirty different pathways that lead to BOS and FOS. Therefore, at the start of BOS and FOS, not only the social and personal background of the students is extremely diverse, but also their academic performance.

\section{THE STUDY SKILLS}

Many times a day, teachers at BOS and FOS may ask themselves [3]: "Are my students prepared for the challenges of postsecondary education?"

Are study skills a means to predict future academic performance [4]? For decades, study skills have been frequently cited in the scientific literature [5]. As a general term, study skills summarize all those activities necessary to manage learning and to handle tests. The basic assumption is that all activities that are directly related to productive class performance at school will determine future academic success at university.

Which of these various activities are particularly important for the specific requirements of applicationoriented learning among BOS and FOS students?

For the schools of Bavaria/ Germany, the BuS program - Beruf und Studium (work and study) - provides the answer to this question [6]. BuS was developed in 2005 by the ISB (State Institute for School Quality and Educational Research) Munich. BuS is a voluntary and systematic program to support the decision-making process on career or degree.

At each upper vocational school, educational and career guidance counsellors assist students and their parents in dealing with the many issues of the transition from school to university. We benefitted from this expert knowledge. 
Based on the BuS and hand in hand with the counselors, we developed a catalogue containing those activities which meet the requirements of upper vocational schools. Finally, this catalogue was cross-checked by the experts responsible for upper vocational schools at the 'Bayerisches Staatsministerium für Bildung und Kultus, Wissenschaft und Kunst', the Bavarian State Ministry of Education and Teaching, Science and Art. In this way, our study skills - and their related activities were established.

\section{A. Teamwork}

The activities related to excellent teamwork are as follows. The students should be able to:

1. enjoy working in cooperation with other learners,

2. keep to an agreement,

3. readily take on responsibility,

4. show empathy for other group members,

5. often take the initiative to introduce their ideas to a group,

6. feel comfortable with presentations in front of a group,

7. make constructive contributions during a discussion,

8. explain complex issues in a comprehensible way.

\section{B. A clear idea of studies at university}

With this set of activities we draw the attention of the students of BOS and FOS to the organizational activities of taking up a degree course. As early as possible, the students should:

1. mindfully choose a suitable field of study and

2 . be acquainted with the application process of their favorite university.

So far, the students of upper vocational schools feel safe with lessons that follow a fixed timetable, which is predetermined by their school. Now, they should develop a clear idea of:

3. the daily routine at university and

4. how a typical lecture at university works.

A review of the state of more than forty years of research on study skills [7] shows that it is one thing to identify effective action; but another to implement it. That is exactly what we strive for. Our research question is: What would it be like, if students at upper vocational school do strengthen their study skills - especially teamwork - at the gateway between school and university?

As a response, we developed the Pupils' Academy with Go4C in the year 2009. The approach is to actively involve the students via a project-based learning scenario. Thus we focus on those activities that best strengthen their study skills.

\section{THE PuPILS' ACADEMY WITH Go4C}

The Pupils' Academy with Go4C is a joint project of the Department of Informatics at the Technical University of Munich TUM and the FOS/ BOS Munich for Technology on behalf of the upper vocational schools of Bavaria/ Germany.

At the end of grade 12, the students of BOS and FOS will sit the German Abitur (see section II). At the end of grade 11 , one year before university actually starts we want the students of upper vocational school to start seeing themselves as future university students. Thus, the participants of the Pupils' Academy are $11^{\text {th }}$ graders.
The Pupils' Academy takes place every year in the week from the end of June to the beginning of July. The Pupils' Academy focuses on a change of perspective: for two days the $11^{\text {th }}$ graders take on the role of a university student. They experience university first hand, but playfully.

So the intention of the Pupils' Academy is to strengthen study skills in order to support the transition from upper vocational school to university. This means that we:

- raise the BOS/ FOS students' awareness of the importance of study skills,

- inform the students at full length about the various activities related to the study skills, and

- offer the students a personal experience of strengthening their own study skills.

As a particularly suitable tool we use the business game Go4C [1]. Nowadays, serious games and especially business games are well established as part of learning scenarios not only for students at schools and universities but for top-level managers, too.

With Go4C the students take their chances as top-level managers of the TechniCar Autobank. By this means Go4C imparts, in an integrated, project-based approach, both business administration skills and the study skills comprising those activities summarized by teamwork and a clear idea of studies at university.

The successful participants of the Pupils' Academy are awarded a certificate issued by the TUM in cooperation with the Bavarian State Ministry of Education and Teaching, Science and Art. Combined with the German Abitur, this certificate may help the students to successfully manage the transition towards university.

\section{The FIVE INTERACTION PHASES OF GO4C}

Go4C is a turn-based business game which was developed in-house at TUM. The scope of Go4C is to practice the application of state-of-the-art information technology to successful management processes within the simulated environment of a company [1]. Go4C has been applied to the Master's in Information Systems and Economics course at TUM since 2001 and the Pupils' Academy with Go4C since 2009.

Have you ever experienced a business game as part of a learning scenario? The learning with business games not only improves technical knowledge. According to research which is described in scientific literature, for example by [8], we experienced Go4C as best suited to acquire not just technical competences but also metacognitive competences like the activities related to teamwork. The unique strength of Go4C is its application oriented learning approach. Therefore, in 2009, Go4C seemed to be the best tool for the students at BOS and FOS to strengthen study skills as presented in section III.

The subject-related goals of Go4C have their roots in the science of applied business information management. A company must be consolidated and its profits and growth should be sustainably developed. From a didactical point of view, Go4C follows a project-based learning approach in the tradition of [9]. As described by [10], Go4C promotes self-regulated learning according to [11] and personalized learning summarized in [12].

The company itself is a virtual bank, called TechniCar whose product portfolio focuses on car financing and savings accounts. The savings will be used to finance the 
loans for cars. The interest rate of the car financing business should be higher than the one related to the savings accounts: the larger the gap between the two rates, the higher the profit. In addition, TechniCar generates profits through transactions on the interbank market.

The user interface of $\mathrm{Go} 4 \mathrm{C}$ is a state-of-the-art management information system (MIS). Through MIS the learners control TechniCar. They carry out business analyses, develop strategies, implement them and evaluate their impact. On the one hand, MIS comprises several hundreds of economic indicators, which are organized through a balance sheet, a profit and loss statement and a Balanced Scorecard as proposed by [13], including data on market/ competition and the staff. On the other hand MIS contains a project management tool.

The administration interface of Go4C enables the game tutors to visualize and compare all indicators over time. We use this feature to evaluate the achievements of the learners at the end of each turn and give them valuable feedback. Thus the learners will enhance their technical and metacognitive abilities with every decision made in the 'played reality' of TechniCar as observed by [14].

Each student of upper vocational schools plays one out of four roles as a top manager of TechniCar: Chief Financial Officer (CFO), Chief Information Officer (CIO), Chief Marketing Officer (CMO) or Chief Operating Officer (COO). Thus, you need four students forming a management board to share control of the company as a management team including any kind of $\mathrm{CxO}$. A Pupils' Academy supports a maximum of four courses, each encompassing up to six management teams.

Each management team competes turn-based and independently of the other teams against a computer scenario. The duration of a turn is determined by the tutors in coordination with the learners. Every turn simulates one half of a fiscal year.

At the start of the business game the (car financing interest) revenues are no longer sufficient in order to cover the (customer savings interest) cost and other expenses. The net income of the last fiscal year is worryingly a negative.

The process flow of Go4C covers five Interaction Phases (see Fig. 1).

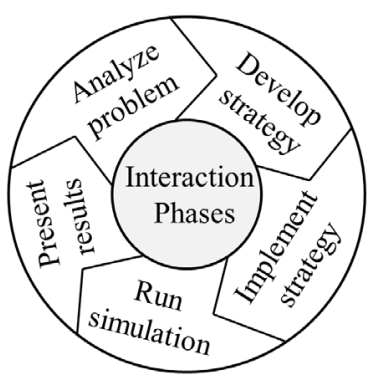

Figure 1. Interaction Phases

These five phases represent in more detail the traditional phased model for teaching and learning as presented by [15] consisting of analyzing, problem solving and feedback/transfer.

1. Analyze the problem: In the first turn of a simulation each management team must strive to understand the current business situation and decide on a business objective for TechniCar, e.g. achieve the highest net income compared to the other teams.

Before starting the second turn it is important to analyze the degree to which TechniCar has met its business objective. What have the results of the last turn been? Which changes in the indicators does the MIS show?

2. Develop a business strategy: A student has to develop a strategy for achieving the business objective. On the one hand this strategy describes the manipulation of single values or business ratios in form of MIS indicators. On the other hand the strategy describes a selection of projects which aim at the continuous improvement of TechniCar's business processes. Ideally, these descriptions include sub-targets for each of the following turns. According to our experience, the learners create a strategy by first phrasing some hypotheses on the current business situation of TechniCar. Then the learners create a spreadsheet in order to anticipate the next turn.

3. Implement the business strategy: On the basis of the strategy and according to their respective area of responsibility within the top management each $\mathrm{CxO}$ implements the appropriate input values to run the company. It is very important that the $\mathrm{CxOs}$ act as a team and coordinate their inputs. Especially the CFOs should ensure that sufficient financial resources are available to finance the business transactions.

4. Run the simulation: When the agreed time has elapsed for the current turn, the user interface is locked. Then the game administrator runs the computer simulation of the current half of a business year. The simulation normally takes about ten minutes.

5. Present the results: Each team receives the results of the computer simulation of their business activities. The participants have to present a target/ actualcomparison on the business situation of their company based on the MIS indicators and the MIS project management summary. This is staged like an executive presentation given by a real management board to the supervisory board. The latter is played by the tutors of the Pupils' Academy. The participants have to answer questions like:

Target: Which business objective was targeted and which business strategy was implemented? Which transactions were carried out? Which projects have been implemented?

Actual: What has actually been achieved and which deviation from the company's target performance exists and what is its underlying cause? What sub-targets will you envisage during the next turns?

After the executive presentation the next turn starts with the first Interaction Phase again. It is due to this iteration of the Interaction Phases that the students of upper vocational schools enhance their study skills. This principle follows the Plan-Do-Check-Act PDCA Cycle of W. Deming [16].

\section{THE DIDACTIC FRAMEWORK OF GO4C}

According to the research of [17] and [18], we have documented our experience with Go4C in the Didactic Framework of Go4C (see Fig. 2). It equals a process flow which is structured in the four stages Preparation, Introduction, iteration of Interaction Phases (see section V) and Conclusion.

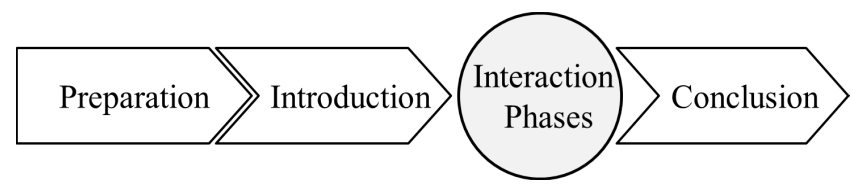

Figure 2. Didactic Framework of Go4C 
The Pupils' Academy may consist of up to seven iterations of the Interaction Phases. Each of the iterations corresponds to a single turn in the turn-based course of the business game Go4C. During the turns, the participants strengthen their study skills according to the activities described in the third section. With each turn, the participants master the game controls of Go4C more and more confidently and understand the business processes of TechniCar better and better.

Following the concept of error management training described by [19], it is important that the participants learn to both recognize and deal with inexpedient strategies, unexpected difficulties or mistakes. Then they may do better during the next turn and their success will be acknowledged.

On the one hand, this allows us to increase the difficulty of the tasks to be solved in Go4C with each turn. On the other hand, instead of teaching technical competences only, we may guide the participants to autonomous learning as proposed by Aviram [20]. Johannes Wildt propagates this "Shift from Teaching to Learning" [21] as the most important didactical approach towards outstanding study skills.

Thus we have given a short overview of the didactic framework of Go4C. The individual stages will be explained below.

\section{A. Preparation}

The first stage called Preparation is for establishing the organizational conditions needed to conduct the Pupils' Academy successfully.

It is very important to brief participants on the objectives of the course. As described in the fifth section, the Pupils' Academy supports a maximum of four courses, each encompassing up to six management teams, i.e. a maximum of 96 students of the upper vocational school altogether. Each course stays at TUM for two days.

There are some legal aspects we have to consider during Preparation. In strictly legal terms each participant of the Pupils' Academy has the status of a student of upper vocational school, not that of a university student. Therefore the school sending a participant must clearly take the disciplinary responsibility and be accountable for all aspects related to insurance-law.

What competences do the participants need in preparation for the Pupils' Academy? They should already have some basic experiences in teamwork, presentations in front of class and in handling technical texts. They need to master the calculation of interest rates. The best way to learn this would be during the lessons on spreadsheet analysis, which are mandatory in the curriculum for the $11^{\text {th }}$ grade of the upper vocational school. We also advise teachers that the participants should analyze a balance sheet and a profit and loss statement based on the example of a real company in preparation for the Pupils' Academy. Thereby the English technical terms should be used according to the glossary of Go4C [1]. According to our experience, Part 1 of the book "Analysis for Financial Management" [22] is best suited for this, notably because of the many examples in the form of computer-based spreadsheets.

\section{B. Introduction}

What are the business challenges that the TechniCar bank has to deal with every day? Which business

processes and respective roles does Go4C offer for managing TechniCar? Answering these two questions is the task of our participants in the second stage named Introduction. The manual and the related FAQs provide the relevant information [1].

The students become acquainted with the roles of the management board and collect their first experiences with the various aspects of the study skills as follows: We use a cooperative learning technique according to the Jigsaw Classroom of [23].

First, four specific expert groups are formed: CFO, $\mathrm{CIO}, \mathrm{CMO}$ and $\mathrm{COO}$. Their respective assignment is to explore their area of responsibility, the operating interface and the business process from the point of view of their management role. The acquired knowledge is to be documented on flip charts. After 45 minutes, the expert groups have to present their results to all participants. We display the flipcharts in the course room to serve as memory aids during the Pupils' Academy.

Second, having finished their presentations, the expert groups dissolve and the participants reassemble in the management board meetings of TechniCar in preparation of the Interaction Phases. Thus, each management board consists of four participants in the roles of CFO, CIO, $\mathrm{CMO}$ and COO. This way, we transfer the expertise on the $\mathrm{CxO}$ roles to each management board. It should be kept in mind that the Pupils' Academy supports a maximum of up to six management teams in a course.

The tutors of the Pupils' Academy play the role of the supervisory board of TechniCar. Thus, they are truly integrated in the business game from the very beginning of the stage Introduction. The tutors are not only able to help the participants with purely technical knowledge, they also provide methodological support from the inside of the "Played Reality". According to their feedback, the participants very much appreciate this collaboration with tutors at "eye level".

\section{Iteration of the Interaction Phases}

The Pupils' Academy as a whole is built on the principle of the flow-theory. With each iteration of the Interaction Phases, the participants are confronted with an even more challenging task [24]. The more they become involved with the played reality of TechniCar and the more they identify with their role in the management board, the more they will be taken away by the flow and the more they will enjoy strengthening their study skills. The more the participants enjoy Go4C as a game and not as a medium for learning [25], the higher their intrinsic motivation to learn will be.

The cognitive processes triggered by each iteration are described according to the taxonomy of educational objectives developed by [26]. We use (Table I) a German nomenclature according to [27].

TABLE I.

NOMENCLATURE

\begin{tabular}{|l|l|l|}
\hline Understand & Verstehen & $\square$ \\
\hline Apply & Anwenden & $\square$ \\
\hline Analyze & Analysieren & $\square$ \\
\hline Evaluate & Auswerten & $\mathbf{\square}$ \\
\hline Create & Erschaffen & $\mathbf{\square}$ \\
\hline
\end{tabular}

Each process is visualized by a symbol. The cognitive process "Understand $\square$ " at the beginning of an iteration means that we give a lecture on the respective theory, e.g. we explain the user interface of the MIS at the beginning of the first iteration.

On the basis of this nomenclature all iterations and their associated knowledge dimensions are listed in Table II. 
TABLE II.

ITERATIONS AND KNOWLEDGE DIMENSIONS

\begin{tabular}{|c|c|c|c|c|c|c|c|}
\hline Knowledge Dimension $\quad$ Iteration & 1 & 2 & 3 & 4 & 5 & 6 & 7 \\
\hline User interface of Go4C & $\square$ & $\square$ & $\square$ & $\square$ & $\square$ & $\square$ & $\square$ \\
\hline Five Interaction Phases & $\square$ & $\square$ & $\square$ & $\square$ & $\mathbf{\square}$ & 口 & $\square$ \\
\hline $\mathrm{CxO}$ roles of the management board & $\square$ & $\square$ & $\square$ & $\mathbf{D}$ & $\square$ & 口 & $\square$ \\
\hline Calculation of interest rates & $\square$ & $\square$ & $\square$ & $\mathbf{D}$ & $\boldsymbol{Q}$ & & \\
\hline Customer savings finance car loans & & $\square$ & $\square$ & 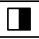 & $\square$ & $\square$ & \\
\hline MIS balance sheet & & & $\square$ & $\square$ & $\square$ & $\mathbf{D}$ & $\square$ \\
\hline MIS profit and loss statement & & & $\square$ & $\square$ & $\square$ &  & $\square$ \\
\hline MIS Balanced Scorecard & & & $\square$ & $\square$ & $\square$ & $\square$ & 口 \\
\hline Human resources management & & & & $\square$ & $\square$ & $\square$ & $\square$ \\
\hline Information management/ IT-infrastructure & & & & $\square$ & $\square$ & $\mathbf{0}$ & $\square$ \\
\hline Business objectives and indicators & & & & & $\square$ & $\square$ & $\square$ \\
\hline MIS project management & & $\square$ & $\square$ & $\mathbf{D}$ & $\square$ & & \\
\hline
\end{tabular}

Each knowledge dimension is related to a couple of new tasks that the participants have to include in the operational business activities of TechniCar by realigning the business objective with the respective strategy after each of the iterations.

The first iteration is for the participants to grow familiar with the user interface of Go4C. Typical questions are: Where can I find what? What indicators does the MIS contain and how can I change their respective values?

How do you implement an operative decision and evaluate its impact? Based on our experience with Go4C, the first presentation of results serves for clarifying those questions. For further assistance we always recommend to look up the FAQs documented in [1].

During the first two iterations, the process flow of the five Interaction Phases is established. Here the assistance of the tutors is more important than during the following iterations. The teams establish their modus operandi and practice communication and cooperation in their respective $\mathrm{CxO}$ roles of the management boards: $\mathrm{CFO}$, CIO, CMO and COO. They learn to present results in a concise and businesslike manner. The first two iterations focus on the consolidation of the liabilities by replacing the central bank credit with an alternative financing solution based on a much lower interest rate. The participants learn how to apply the mathematical basics of the calculation of interest rates to the situation of TechniCar: Is it possible to finance TechniCar without any central bank loans?

With questions like, "Which tasks do I have to perform to manage a car financing bank?", the tutors lead the participants towards deciding on sound business objectives for TechniCar at the start of the second iteration: e.g. profit leader, cost leader, market leader. They should develop a reasonable strategy based on the principle: customer savings finance car loans. This strategy should be implemented and - if necessary further improved during the following iterations.

Go4C comprises a total of about a thousand different financial and non-financial indicators that are linked with each other by means of System Dynamics [1]. Participants must follow up on these indicators during the iterations. But it is not possible to keep track of a thousand indicators at a time. The participants have to learn to focus on the key indicators. Therefore it is important that the participants gradually learn to keep record of the progress of those indicators that are relevant according to their individual business objective and strategy.

Each iteration ends with the fifth Interaction Phase 'present the results'. Here the tutors - playing the part of the supervisory board - guide the management boards to:

- Realign discrepant actual results with the targeted objective and learn from the knowledge gained [19]

- Integrate a new task into their business strategy, i.e. one of those tasks that are related to the next knowledge dimension according to Table II.

From our experience, you should choose the MIS balance sheet, profit and loss statement and the Balanced Scorecard as the central topics to discuss from the third iteration on. Beginning with the fourth iteration, the knowledge dimensions human resources management and information management/ IT infrastructure should be addressed. Is net income the very best objective of entrepreneurship or are there additional business objectives, which describe business excellence even better? Which business indicators support these objectives? These questions should be explored beginning with the fifth iteration.

Over the years, we have developed a whole set of different scenarios for Go4C. This paper presents a scenario focusing on the very special project management feature of Go4C as a tool to strengthen study skills: Starting with the second iteration, the participants rely on project management (see section VII) to optimize the performance of the business processes of TechniCar, thereby increasing the net income significantly.

Additional to the participants' management boards, the tutors simulate their own TechniCar. The participants may use this Go4C-Benchmark as a blue-print solution. Thus, we give valuable feedback and provide hints for reconstructing the System Dynamics Model of TechniCar [1] in the form of spreadsheets. Having finished the seventh iteration we continue with the stage Conclusion.

\section{Conclusion}

At the stage Conclusion, each management board summarizes their business objectives, strategies and the key measures that account for the company's success. The teams reflect on the knowledge dimensions and both their successful and not successful decisions. Each statement should be justified by the proper indicators of the MIS, following the structure established by the balance sheet, profit and loss statement and the Balanced Scorecard.

The entire final presentation is staged as an executive summary addressed to the supervisory board. The supervisory board assesses the executive summaries according to the indicators net income, customer quality, processing time, market share and number of employees. The most successful approaches to Go4C are based on two pillars: consolidate TechniCar first and then ensure its sustained economic success. Typically, good teams master the consolidation by the third iteration. After the fifth iteration, all teams succeed in increasing the net income from an initial loss of 26 million U.S. dollars to a profit of up to 75 million U.S. dollars per half-year. As integral part of the executive summaries, we encourage the participants to reflect - in addition to the business related aspects - on their key learnings related to the study skills. 


\section{How GO4C STRENGTHENS STUDY SKILLS}

Now we are ready to answer the central question of this paper: How does the study skill 'teamwork' correspond with the Didactic Framework of Go4C?

TABLE III.

STUDY SKILL 'TEAMWORK’ AND DIDACTIC FRAMEWORK

\begin{tabular}{|c|c|c|c|c|c|c|}
\hline Teamwork activities & 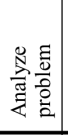 & 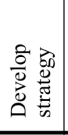 & 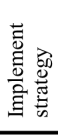 & 昰兽 & 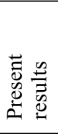 &  \\
\hline Enjoy working in cooperation & & & & & & \\
\hline Keep to an agreement & & & & & & \\
\hline Take on responsibility & & & & & & \\
\hline Show empathy for group members & & & & & & \\
\hline Introduce ideas to a group & & & & & & \\
\hline Feel comfortable with presentations & 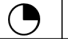 & 9 & 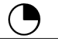 & & & \\
\hline Make constructive contributions & & & & & & \\
\hline Explain complex issues & & & & & & \\
\hline
\end{tabular}

\section{A. Teamwork and Didactic Framework}

Table III shows how the Interaction Phases and their iterations are related to the eight activities of teamwork.

The pie charts visualize to what extent a phase helps to master one of the activities. The more the pie is shaded the stronger a phase is connected to an individual activity. By choosing this kind of visualization we refer to the representation of the learning objectives according to [26]. Thus the table lists the very heart of the curriculum of the Pupils' Academy.

As an example we will rely on a scenario based on Customer Savings and Car Financing Loans. By dealing with this scenario, an example will now illustrate how the study skills interact with Go4C's Didactic Framework.

Based on the balance sheet of TechniCar (example see Fig. 3) and its related profit and loss statement, the CFO analyzes the interest rates for T-Bill and T-Bond Securities, Reverse Repurchase Agreements (Repos), Bank Loan Assets, Car Financing Loans, Central Bank Advance, Repos, Bank Loan Liabilities and Customer Savings [1].

Then the CFO explains her management colleagues that the revenues are no longer sufficient to cover the expenses due to the expensive Central Bank Advance (18\%). As a consequence, the net income will be a negative. The main objective for the management boards should be to develop a sound solution for the liabilities without Central Bank loans. So - with a little bit of logical reasoning and excellent teamwork the management boards will develop a successful strategy.

\section{B. How projects strengthen teamwork}

This strategy development begins with the CFO asking: "Which investments would now be useful in order to finance the Car Financing Loans CFL with low-interest Customer Savings CS thus sustainably increasing the net income?" Go4C's Interaction Phases will guide us towards a sound solution of this problem.

As a first step, in the phase Analyze, CIO, CMO and COO establish adequate objectives particularly with regard to the non-financial indicators of the MIS Balanced Scorecard. As a second step, CIO, CMO and COO dev-

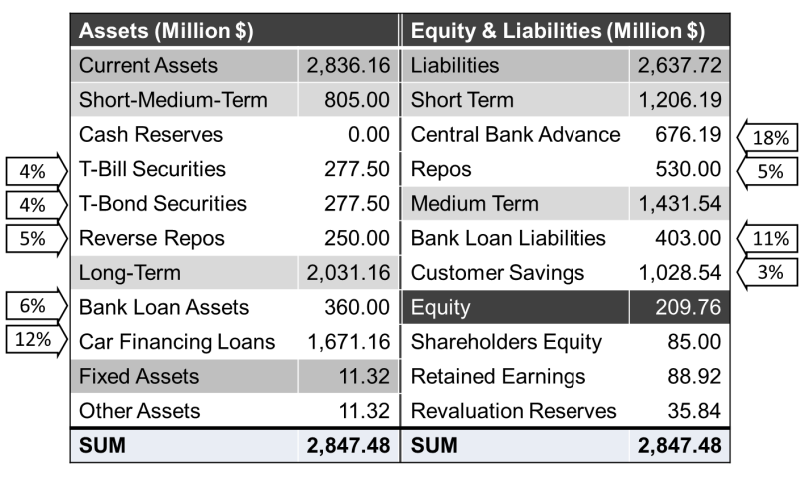

Figure 3. Example balance sheet of TechniCar

elop a strategy which is consistent with these objectives. Go4C's MIS project management PM supports this step by providing the functions Project Repository, Effect Matrix and Resource Allocation.

The Project Repository is a collection of Work Packages WP, along with preconditions and constraints (Fig. 4). A WP can be started if all its preconditions are met, and will unfold its full impact only if all its constraints are taken into account.

\begin{tabular}{|l|l|l|l|}
\hline \multicolumn{5}{|c|}{ Project Repository - Work Packages } \\
\hline ID & Description & Precondition & Constraint \\
\hline WP1 & Car Financing Loans initiative & & WP2, WP3 \\
\hline WP2 & Train Production staff & & \\
\hline WP3 & Use workflow management system & WP4 & \\
\hline WP4 & Modernize IT infrastructure & & \\
\hline WP5 & Customer Savings initiative & & WP6, WP8 \\
\hline WP6 & Implement cross- and upselling & WP7 & \\
\hline WP7 & Implement CRM process & WP4 & \\
\hline WP8 & Train Marketing staff & & \\
\hline
\end{tabular}

Figure 4. Example of a Project Repository and its Work Packages

The Effect Matrix outlines the impact of a specific WP on TechniCar's organization (see Fig. 5). This is an estimate because it would be impossible to capture all, often elusive, interactions between a work package and the organization.

With the help of the MIS indicators and the WPs, the CxOs formulate the following exemplary strategy. For the sake of clarity, Figure 6 models this strategy as a diagram. It should be noted that Go4C relies on a System Dynamics modelling approach to implement the preconditions, constraints und effects.

WP1: The first objective is defined by the COO: "Increase the number of successfully completed CFLs."

WP2. The employees of the COO's Production Department often fail to process customer requests correctly. Adequate staff training is needed to avoid revision and increase the first pass yield (FPY个).

WP3. In addition, significantly more customers request a CFL than Production can process. The CIO's state-of-the-art work flow management system will optimize production processes thus increasing the number of business

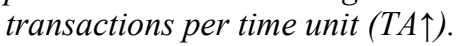




\begin{tabular}{|l|c|c|c|c|}
\hline \multicolumn{5}{|c|}{ WP7 Implement CRM process } \\
\hline Organization Effect & Process & Knowledge & Risk & Information \\
\hline Entire bank & & & & \\
\hline Marketing & & & & \\
\hline Production & $\begin{array}{c}\text { medium } \\
\text { effect }\end{array}$ & $\begin{array}{c}\text { strong } \\
\text { effect }\end{array}$ & $\begin{array}{c}\text { no } \\
\text { effect }\end{array}$ & $\begin{array}{c}\text { weak } \\
\text { effect }\end{array}$ \\
\hline IT & \multicolumn{1}{|c|}{ iT }
\end{tabular}

Figure 5. Effect Matrix of Work Package WP7

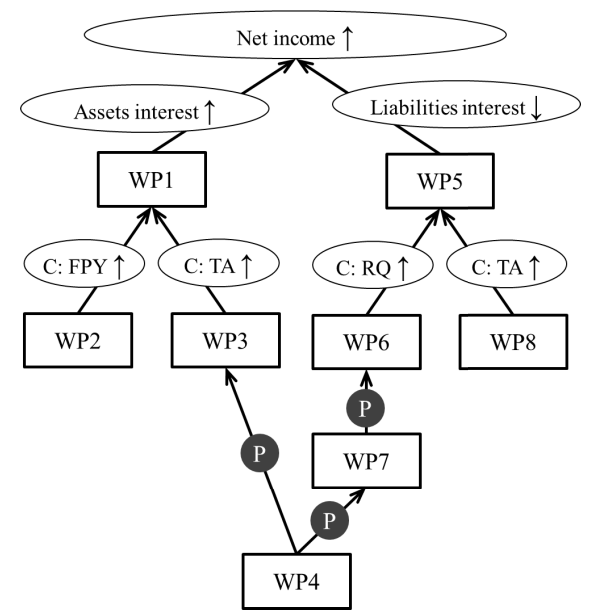

Figure 6. Exemplary strategy to finance Car Loans

WP4. The precondition $\mathrm{P}$ is that the CIO strives to modernize the on average five-year-old IT infrastructure.

WP5: The CFO establishes the second objective: "Increase the ratio of CS to liabilities."

WP6. In future, the CMO's Marketing Department will strive for cross- and upselling. The CS product will be offered to existing CFL clients, their friends and acquaintances. This will increase the

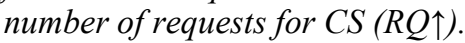

WP7. The precondition for cross- and upselling is that both departments, COO's Production and CMO's Marketing, have access to all customer data. Therefore, the CIO has to implement a customer relationship management CRM process. Its precondition is the modernized IT infrastructure from WP4.

WP8. Adequate training of CMO's Marketing staff will ensure that the number of cross and up-selling transactions really is increased (TA $\uparrow)$.

This example illustrates how the Go4C projects enhance the participants' teamwork skills (section III.A). To master the development of the strategy shown in Figure 6, the participants must enjoy working in cooperation with each other and show empathy. They must often take the initiative to introduce their ideas to their fellow management colleagues, thereby feeling comfortable with presentations. The participants have to make constructive contributions during a discussion and explain complex interdependencies of a WP in a comprehensible way.
As a third step, this strategy must be implemented. For this purpose each WP must be assigned its required resources by means of the PM function Resource Allocation. Here the participants must keep to the agreement and readily take on responsibility to implement a WP according to its business impact.

\section{The RESUlts of THE PUPILS' ACADEMY}

How well does the Pupils' Academy with Go4C strengthen study skills? And in particular - how well does the project management feature of Go4C enhance the study skill of teamwork? We reviewed the effectiveness of the Pupils' Academy with a computer based questionnaire. All participants rated their own study skills before and after attending the Academy. We visualized the results of this rating by comparing both estimates for each of the activities of the study skills.

For the IT-based questionnaire, the various aspects of the study skills were converted into first-person statements, e.g. "I enjoy working in cooperation with other learners". The rating of each statement is based on a Likert scale, comprised of five (dis)agreement levels ranging from strongly agree $(\square)$ to strongly disagree $(\square)$.

The participants took about 15 minutes for carefully processing the entire questionnaire. Usually, we interpreted the results of the survey together with the participants at a workshop held one week after the Pupils' Academy.

\section{A. Results on teamwork}

The students formulated the most important condition for acquiring teamwork (see Fig. 7) as follows: "The complexity of the business game was so overwhelming that we didn't understand anything during the first turn", but then "... with all the fantastic ideas from our group from the third turn on we got the knack!" The turn-based approach of the game leads to success.

Participants not only recognize but admit and correct their own mistakes. The data basis for this improvement is the MIS of Go4C - especially the project management. During the first two iterations, the students experience the MIS as an unfamiliar, complex system. The more they deal with the MIS in the following turns, the more they treasure it as an "essential and indispensable aid". A student summarizes her overall judgment, "I had to work in a concentrated way and under pressure for two days. Nevertheless, I had a lot of fun." With the 5th turn each team managed to lead TechniCar towards success. "Wow - we just raised the bar: our net income increased to 75 million U.S. dollars," a participant rejoiced.

\section{B. Results on a clear idea of studies at university}

The Pupils' Academy prompts the students of the upper vocational schools to get a clear idea of studies at university (see Fig. 8). They tell us, "Before the Academy, I thought: 'I know everything that is important about studying'. Afterwards, I see far more clearly what studying really means."

Our key finding is: the $11^{\text {th }}$ graders of upper vocational schools BOS and FOS do not have a very clear idea of their future after school.

The unanimous opinion is: "First thing I have to do is to obtain the university entrance certification. Afterwards I'll deal with all the organizational details of an application at 


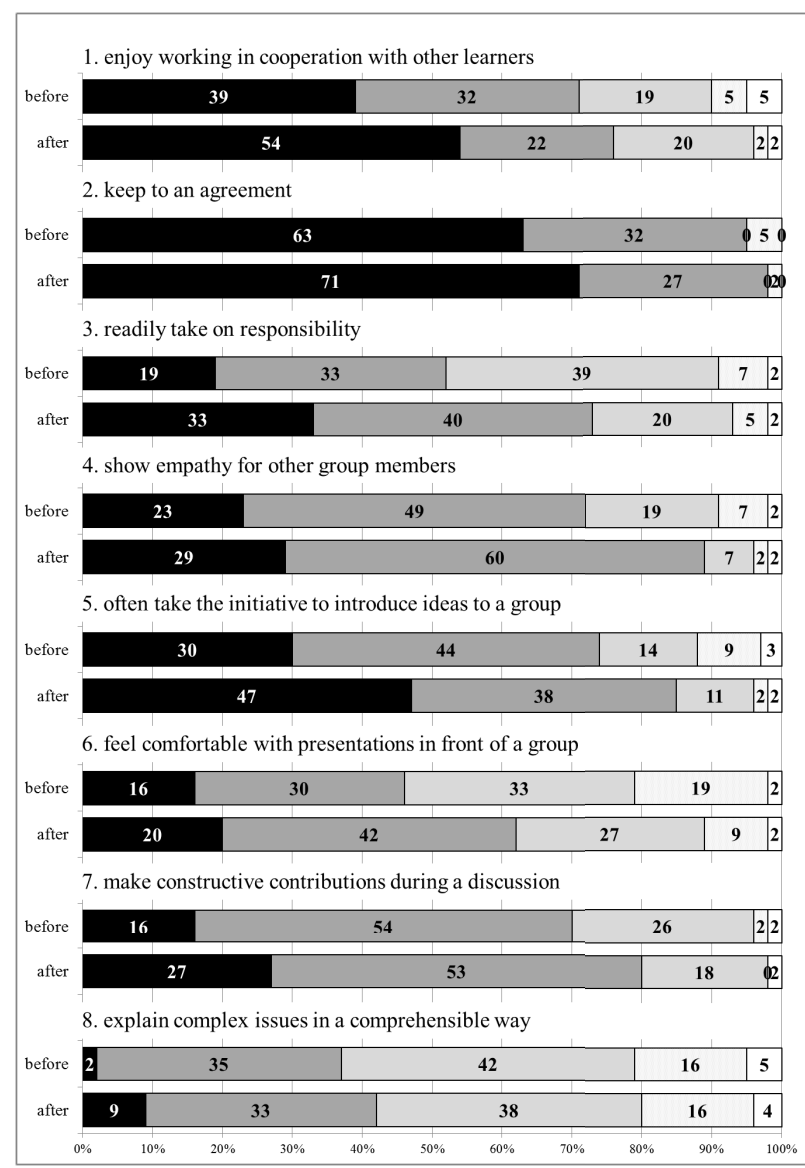

Figure 7. Rating results on teamwork

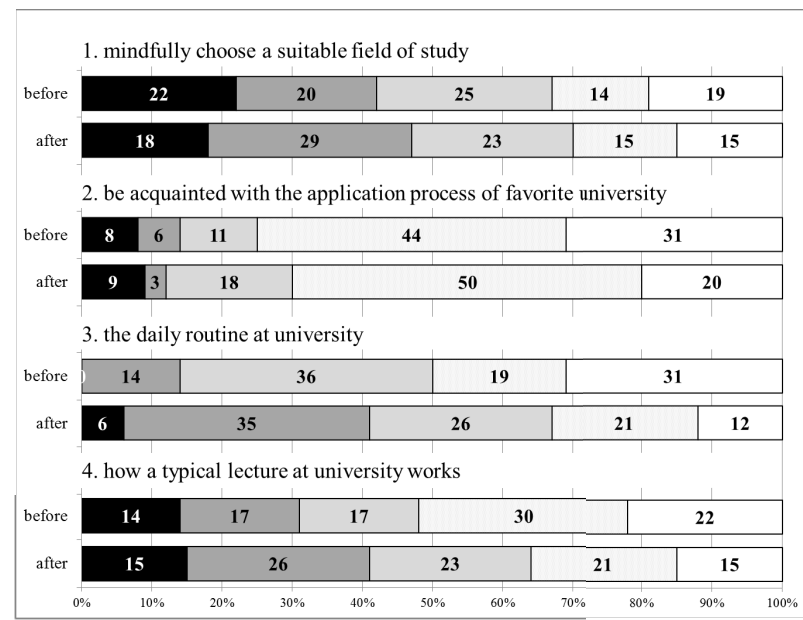

Figure 8. Rating results on a clear idea of studies at university

university." That is precisely the starting-point of the Pupils' Academy. The $11^{\text {th }}$ graders live at university for two days under real conditions of studying - one year before they actually graduate. This inspires them to seek a clearer idea of studies at university.

\section{Comparison of the Abitur results}

The questionnaire on the study skills gave us valuable hints for improving the Pupils' Academy. In addition, it leads the $11^{\text {th }}$ graders to deal with the activities of the study skills in depth. Nevertheless, the questionnaire, like any evaluation depending on the participants' self-assess-

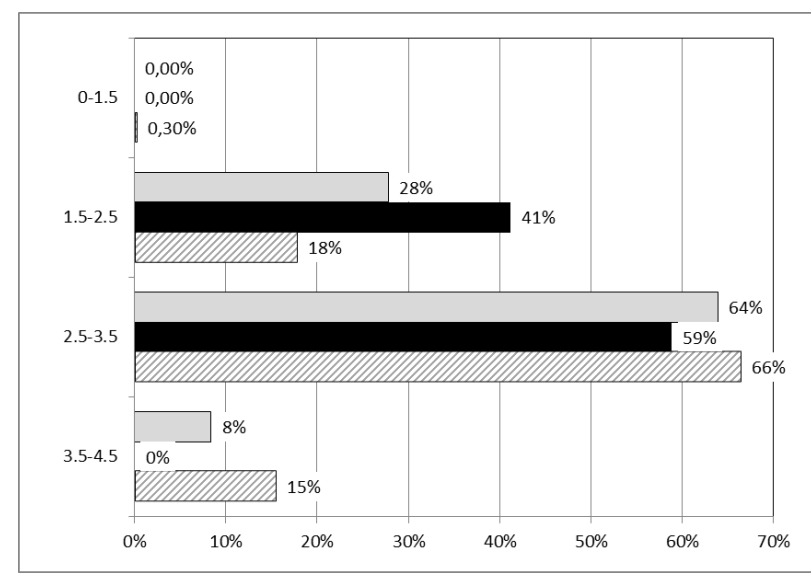

Figure 9. Abitur result comparison 2014/ 2015

ment, offers - from a scientific point of view - little information about what the $11^{\text {th }}$ graders actually gained.

What other indicators are suitable to evaluate the success of the Pupils' Academy? In response to this question, in the year 2013, we started to explore another indicator: the results of the final exam, the German Abitur (see Fig. 9).

To clarify this approach further: In 2014, the former $11^{\text {th }}$ graders who had participated in the Pupils' Academy in 2013 were in grade 12, which ends with the Abitur. Thus we use all 401 graduates of FOS/ BOS Munich for Technology of the school year 2014 as control group $\square$.

Can we compare the Abitur of the Pupils' Academy participants with the control group's Abitur as an indicator of the success of the Pupils' Academy? As a basis for this we invited two different groups of $11^{\text {th }}$ graders to the Pupils' Academy. Group-I $\square$ was an entire class whose grade records were representative of grade 11 students. Group-II consisted of highly talented students who were proposed at a teachers' department meeting.

Fig. 10 compares the 2014 and 2015 Abitur results of group-I and group-II with the control group on a scale of 1 to 4 (1=excellent, 2=good, 3=satisfactory, $4=$ pass mark/ sufficient). This comparison suggests that the Abitur 2014 and 2015 grades of the Pupils' Academy participants show an improved average of 2.73 compared with an average of 2.97 for the control group. 2014 the participants of the Pupils' Academy achieve a lower failure rate of $0.09 \%$ compared to $16.21 \%$ in the control group. Based on the results of this comparison, we decided to keep on collecting and analyzing the Abitur results for each participant of the Pupils' Academy in addition to the questionnaire on the study skills.

\section{CONCLUSION}

In June 2015 was the six year anniversary of students of the upper vocational school participating in the Pupils' Academy with Go4C. Does the Pupils' Academy achieve the ambitious goal of strengthening the students' study skills - especially teamwork - at the gateway between upper vocational school and university?

Improving the study skills requires the students to change their learning behaviors. The Pupils' Academy takes two days. On the one hand, that is nowhere near enough time to master all activities related to the study skills. But on the other hand, it definitely is sufficient time to raise the students' awareness and to provide detailed 
information on particularly important activities, like the eight activities of the teamwork.

A notable aspect of the turn-based approach of Go4C is the project management function PM. The more iterations the participants train the skills of successful teamwork via $\mathrm{PM}$, the more they integrate these skills into their personal working methodology. It is clearly an indicator for this observation that the time needed for a single iteration of Go4C can be constantly reduced. The first iteration lasts up to two hours, while the seventh iteration requires only 45 minutes. In spite of that time reduction, the participants master the tasks according to schedule and successfully, although the tasks are getting more and more complex with each iteration.

As a part of their regular lessons at school, the students of the upper vocational schools experience technical content and learning methods from the perspective of a university. They master the first steps towards adjusting their learning behaviors to university needs with professional assistance. They experience the first successful behavioral changes thus increasing their selfconfidence. Each student is given a fresh impetus to further enhance their study skills autonomously. The students phrase it this way: "In future I'll be striving to further improve my study skills."

\section{ACKNOWLEDGMENT}

The author would like to thank Mrs. Kathrin Füller, Mrs. Zuzana Rosenberg, Mr. Robert Heininger and Mr. Thomas Wolfenstetter for running the Pupils' Academy, Dr. Gudrun Innertsberger for supporting the analysis of data and Mr. Andreas Sirch, and Mrs. Rebekka Utesch for their contribution to reviewing the article. Finally, I would like to express special thanks to Professor Dr. Helmut A.O. Krcmar: with your help, the Pupils' Academy became reality.

\section{REFERENCES}

[1] H. Krcmar und M. Utesch, Planen und Entscheiden: Das Planspiel Go4C, München: Books on Demand, 2011.

[2] B. Staatsministerium, „Schule und Bildung in Bayern: Statistische Übersichten,“"München, 2014.

[3] S. Ferret, Peak performance: Success in college and beyond, New York: Glencoe/ McGraw-Hill, 2000.

[4] R. E. Mathiasen, „Predicting college academic achievement: A research review,“ College Student Journal, Bd. 18, pp. 380-386, 1984.

[5] S. B. Robbins, K. Lauver, H. Le, D. Davis, R. Lanfley und A. Carlstrom, „Do Psychosocial and Study Skill Factors Predict College Outcomes? A Meta-Analysis,“ Psychological Bulletin, Bd. 130, Nr. 2, p. 261-288, 2004. http://dx.doi.org/10.1037/00332909.130.2.261

[6] ISB, Beruf und Studium - BuS, München: Kastner AG - das medienhaus, 2005.

[7] V. Tinto, „Research and Practice of Student Retention: What next? “" J. College Student Retention, Bd. 8, Nr. 1, pp. 1-19, 20062007. http://dx.doi.org/10.2190/4YNU-4TMB-22DJ-AN4W

[8] E. Klopfer, Augmented Learning: Research and Design of Mobile Educational Games, Education next, 2008.

[9] J. Piaget, „Problems of Equilibration,“ In Appel, M. H and Goldberg, L. S. (1977). Topics in Cognitive Development, Volume 1: Equilibration: Theory, Research and Application, Plenum Press, NY, pp. 3-13, 1977.

[10] M. Utesch, D. Bösl, P. Boscolo und C. Helfer, „Erfahrungsbericht zu Serious Gaming - C\# Entwicklung mit AntMe!,“ Embedded Software Engineering Kongress ESE, pp. 611-616, 2009.
[11] B. J. Zimmermann, „Self-Regulated Learning and Academic Achievement: An Overview,“ Educational Psychologist, Nr. 25(1), $\quad$ pp. $\quad 3-17, \quad 1990$. http://dx.doi.org/10.1207/s15326985ep2501 2

[12] OECD, „Schooling for Tomorrow - Personalising Education,“ OECD Publishing, Paris, 2006.

[13] R. S. Kaplan und D. P. Norton, Balanced Scorecard: Translating Strategy into Action, Boston: Harvard Business School Press, 1996.

[14] O. Graven und L. M. MacKinnon, „Exploitation of games and virtual environments for elearning," in Ultimo: ITHET7th International Conference on Information Technology Based Higher Education, 2006.

[15] W. McKeachie und M. Svinicki, McKeachie's Teaching Tips, Belmont: Wadsworth, 2013.

[16] W. Deming, Out of the crisis, Cambridge, MA: Massachusetts Institute of Technology, Center for Advanced Engineering Study, 1986.

[17] P. Pivec, „Game-based Learning or Game-Based Teaching,“ in Becta, 2009.

[18] R. Garris, R. Ahlers und J. E. Driskell, „Games, Motivation, and Learning: a Research and Practice Model," Simulation \& Gaming, pp. 441-467, December 2002. http://dx.doi.org/10.1177/1046878102238607

[19] N. Keith und M. Frese, „Effectiveness of error management training: A meta-analysis," Journal of Applied Psychology, p. 93, 2008. http://dx.doi.org/10.1037/0021-9010.93.1.59

[20] A. Aviram, Navigating Through the Storm: Reinventing Education for Postmodern Democracies, Rotterdam: Sense Publishers, 2010.

[21] U. Welbers, The Shift from Teaching to Learning, Bielefeld: W. Bertelsmann Verlag, 2005.

[22] R. C. Higgins, Analysis for Financial Management, New York: McGraw-Hill, 2009.

[23] E. Aronson und P. Shelley, Cooperation in the Classroom, The Jigsaw Method, London: Addison-Wesley Educational Publishers, 2011.

[24] M. Csíkszentmihályi, Flow: the Psychology of Happiness, London: Random House, 1992.

[25] N. Peirce, O. Conlan und V. Wade, „Adaptive Educational Games: Providing Non-invasive Personalised Learning Experiences," in Second IEEE International Conference on Digital Game and Intelligent Toy Enhanced Learning, Banff, 2008. http://dx.doi.org/10.1109/DIGITEL.2008.30

[26] L. Anderson und D. Krathwohl, A Taxonomy for Learning, Teaching, and Assessing. A Revision of Bloom's Taxonomy of Educational Objectives, New York: Addison Wesley Longman, 2001.

[27] A. Böttcher und M. C. Utesch, „Software Engineering: Zeitgemäße Lern- und Lehrstrategien. Pair Teaching und Bloom'sche Taxonomie,“ in Embedded Software Engineering Kongress, Sindelfingen, 2009.

\section{AUTHOR}

M. C. Utesch is with the upper vocational school 'Staatliche Fachober- und Berufsoberschule Technik', Bergsonstraße 109, 81245 Munich and with the Chair for Information Systems, at 'Technische Universität München', Faculty of Informatics, institute for Information Systems, Boltzmannstr. 3, 85748 Garching, Germany (e-mail: utesch@in.tum.de). He was a member of the Core Advisory Board of the EU Sixth Framework Programme/ iclass. His main interests include IT-based learning, games engineering and in particular the enhancement of the study skills at the interface between school and university.

This article is an extended and modified version of a paper presented at the International Conference on Interactive Collaborative Learning (ICL2015), held 20-24 December 2015, in Florence, Italy. Submitted 12 December 2015. Published as resubmitted by the author 28 January 2016. 